\section{Kidney \\ Blood Pressure Research}

\title{
Uric Acid Levels and All-Cause Mortality in Peritoneal Dialysis Patients
}

\author{
Sheng Feng Linseng Jiang Yongbing Shi Huaying Shen Xiaosong Shi \\ Donghua Jin Ying Zeng Zhi Wang
}

Department of Nephrology, Second Affiliated Hospital of Soochow University, Suzhou, China

\author{
Key Words \\ Mortality $\cdot$ Peritoneal dialysis $•$ Uric acid
}

\begin{abstract}
Background: Epidemiological studies have shown that hyperuricemia is associated with allcause and cardiovascular mortality in chronic kidney disease (CKD) and hemodialysis patients. Our study investigated the influence of serum uric acid (UA) levels on survival in peritoneal dialysis (PD) patients. Methods: This was a retrospective study involving 156 subjects who had undergone PD. The patient demographics, etiology of ESRD, comorbid conditions and other laboratory parameters were collected. The subjects were divided into three groups according to their serum UA concentrations (group 1, the lowest quartile; group 2, the middle quartiles; group 3, the highest quartile). The risk of death was calculated using a multivariate Cox regression model. Results: There were 41 deaths during a follow-up period of $31.3 \pm 17.5$ months. Compared with group 2, which had a mortality rate of 5.7 per 1000 person-months, the mortality rates were higher in group 1 (14.3 per 1000 person-months, $p<0.05)$ and group 3 (13.3 per 1000 person-months, $p<0.05)$. A multivariable Cox regression model revealed that age, serum albumin, diabetes mellitus (DM), hypertensive nephropathy, residual renal function and UA group were factors associated with mortality in the PD patients. Using group 2 as a reference, the hazard ratio (HR) of mortality was found to be 1.15 (95\% confidence interval [CI] 0.20-2.57, p>0.05) for group 1 and 2.96 (95\% CI 1.29-6.80, $p=0.01$ ) for group 3. Conclusions: In PD patients, a higher serum UA level is related to increased mortality and is an independent risk factor for all-cause mortality. Uric acid levels and allcause mortality in peritoneal dialysis patients.
\end{abstract}

Copyright $@ 2013$ S. Karger AG, Basel

\section{Introduction}

An elevated serum uric acid (UA) concentration is frequently encountered in patients who are diagnosed with chronic kidney disease (CKD). Epidemiological studies have identified an association between hyperuricemia and cardiovascular risk in the general 


\section{Kidney \\ Blood Pressure Research}

Kidney Blood Press Res 2013;37:181-189

\begin{tabular}{l|l}
\hline DOI: $10.1159 / 000350143$ & (c) 2013 S. Karger AG, Basel
\end{tabular}

Publisned onirne: IVIral ZI, 2013

www.karger.com/kbr

Feng/Jiang/Shi/Shen/Shi/Jin/Zeng/Wang: UA Levels and All-Cause Mortality in PD Patients

population and in CKD patients [1-4]. In hemodialysis patients, prior single-center studies have revealed a J-shaped relationship between UA levels and mortality [5, 6]. Two other studies have demonstrated that a lower UA level is associated with a higher risk of all-cause and cardiovascular mortality in hemodialysis patients [7, 8].

To date, there has been no study on this topic in patients who had undergone peritoneal dialysis (PD). Previous studies have demonstrated that hyperuricemia can injure endothelial function [9] and cause rapid decrease in residual renal function [10], which are risk factors for cardiovascular events and dialysis inadequacy, eventually causing poor outcome in PD patients. Our study investigated the relationship between serum UA levels and all-cause mortality in PD patients.

\section{Subjects and Methods}

\section{Patients}

This was a retrospective, longitudinal, observational study that included all the patients who began PD between January 1, 2007 and March 31, 2010. Patients' outcomes were documented until March 31, 2012. The patient demographics, etiology of ESRD, comorbid conditions and PD duration were obtained from the patient records and a computerized database in our unit. Transfer to hemodialysis, renal transplantation and death were defined as endpoints. Death during PD and within three months after conversion to HD was regarded as PD-related mortality. Patients who were transferred to HD or transplantation were censored from the patient survival analysis. The exclusion criteria included the following: (1) a PD duration of less than three months; (2) inadequate follow-up clinical information; (3) a history of renal transplantation; and (4) clinically diagnosed cirrhosis. The study protocol was approved by the ethics committee of our institution.

\section{Comorbidity Assessments}

Comorbidities were determined using the following criteria: hypertension was diagnosed as a systolic blood pressure of $\geq 140 \mathrm{~mm} \mathrm{Hg}$ and/or a diastolic blood pressure of $\geq 90 \mathrm{~mm} \mathrm{Hg}$ or the receipt of antihypertensive treatment; Diabetes mellitus (DM) was confirmed by a documented medical history and/ or underlying diabetic nephropathy; congestive heart failure was confirmed by a documented medical history or ultrasonic cardiography showing a left ventricular ejection fraction $<40 \%$; ischemic heart disease was confirmed by a documented medical history of coronary artery disease, myocardial infarction, coronary artery bypass surgery, angioplasty or abnormal angiography; Cerebrovascular accidents were confirmed by clinical symptoms, computed tomography and magnetic resonance angiography and/or cerebrovascular angiography findings; liver cirrhosis was diagnosed by abdominal ultrasonographic findings; and malignancies were confirmed by a documented medical history and/or pathological reports.

\section{Collection of Clinical Characteristics}

Fasting blood samples were obtained from all of the subjects before they began PD and 3 months after initiating PD. Serum UA levels were determined by the uricase-peroxidase method [11].

Follow-up data from all subjects, including their serum UA, KT/V, residual renal function and D/P creatinine ratios at four hours, were collected at our center.

\section{Statistical Analysis}

Continuous variables are presented as the means \pm SD, and categorical variables are expressed as percentages unless otherwise indicated. Student's t-test was used for comparisons of continuous variables between two groups. Correlations were tested using the Pearson correlation method. The KolmogorovSmirnov test was used to analyze the distribution of continuous data for the presence of a normal distribution. The relationships between two or more groups of data were analyzed using the Pearson chi-squared test. Survival curves were generated by the Kaplan-Meier method and were compared by the log-rank test. Factors predictive of all-cause mortality were identified with a Cox regression. Factors with $\mathrm{p}<0.10$ after univariate analysis were entered into the multivariable Cox regression model. A backward elimination procedure with removal set at $\mathrm{p}>0.05$ was performed to identify independent predictors of all- 


\section{Kidney Blood Pressure Research}

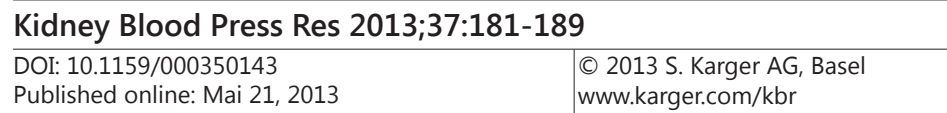
www.karger.com $/ \mathrm{kbr}$

Patients

cause mortality in the dialysis patients. All the analyses were performed using SPSS 13.0 for Windows (SPSS Inc., Chicago, IL, USA), and $\mathrm{p}<0.05$ was considered to be statistically significant.

\section{Results}

Eight patients were transferred out of the unit with nofollow-upclinicalinformation, one was diagnosed with cirrhosis at the beginning of PD, and six subjects died within three months after beginning PD. A total of 156 incident subjects were eligible for the final analysis. The mean duration of treatment was 31.3 \pm 17.5 months (range 3-75 months). Of the 171 incident subjects who were referred to the dialysis center during the study period, 120 patients underwent CAPD and 51 underwent DAPD. None of the patients underwent APD because of their medical insurance policies.

\section{Patient Characteristics}

Among the study subjects, $37 \%$ were female $(n=58)$, and $63 \%$ were male $(n=98)$.The mean age of the subjects was $54.1 \pm 17.4$ years. Additional demographic characteristics, the etiology of the ESRD, comorbid conditions, and the laboratory characteristics of the patients are shown in Table 1.

Ninety-five (61\%) of the subjects had glomerulonephritis, $24(15 \%)$ had diabetic nephropathy, $18(12 \%)$ had hypertensive nephropathy, $4(3 \%)$ had acquired obstructive uropathy, $6(4 \%)$ had polycystic kidney disease, $2(1 \%)$ had lupus nephritis, and 7 (4\%) had unknown causes.

\section{Causes of Death and Technique Failure}

There were 41 subjects who died, of whom 23 died of cardiovascular events, including cardiac arrest $(n=11)$, acute myocardial infarction $(n=3)$, cardiac arrhythmias $(n=2)$, heart failure $(n=4)$ and stroke $(n=3)$. Nine subjects died of infection, of whom four died of sepsis, two died of pneumonia, and three died of peritonitis. The other nine subjects died of cachexia $(n=3)$, gastrointestinal bleeding $(n=1)$ and unknown causes $(n=5)$. There were 19 subjects who were transferred to hemodialysis for reasons including ultrafiltration failure $(n=8)$, refractory heart failure $(n=5)$, recurrent peritonitis $(n=4)$ and tunnel infection $(n=2)$. Five subjects underwent renal transplantation during the follow-up period.

\section{UA Levels and Mortality}

The results of the Kolmogorov-Smirnov test indicated that the serum UA values followed a normal distribution. The mean serum UA level was $8.5 \pm 2.1 \mathrm{mg} / \mathrm{dl}$ (range $3.4-14.3 \mathrm{mg} / \mathrm{dl}$ ). There was no significant difference between the serum UA of the male cohort $(8.6 \pm 2.1 \mathrm{mg} / \mathrm{dl})$ and the female cohort $(8.3 \pm 2.1 \mathrm{mg} / \mathrm{dl})(\mathrm{p}=0.437)$. The subjects diagnosed with diabetic nephropathy had a lower serum UA level $(7.9 \pm 2.3 \mathrm{mg} / \mathrm{dl})$ than those with no diabetic nephropathy $(8.7 \pm 2.0 \mathrm{mg} / \mathrm{dl}, \mathrm{p}=0.027)$. Mean concentrations for group 1,2 and 3 were $5.9 \pm 1.0 \mathrm{mg} / \mathrm{dl}, 8.4 \pm 0.8 \mathrm{mg} / \mathrm{dl}$ and $11.3 \pm 1.0 \mathrm{mg} / \mathrm{dl}$, respectively.

We transformed the serum UA levels into a categorical variable that comprised three serum UA groups, which were arbitrarily defined according to the percentile of the serum UA levels as follows: group $1, \leq 25^{\text {th }}$ percentile (UA $\leq 7.0 \mathrm{mg} / \mathrm{dl}, \mathrm{n}=39$ ); group $2,26^{\text {th }}-75^{\text {th }}$ percentile $(7.0<\mathrm{UA}<10.0 \mathrm{mg} / \mathrm{dl}, \mathrm{n}=78)$; and group $3, \geq 76^{\text {th }}$ percentile $(\mathrm{UA} \geq 10.0 \mathrm{mg} / \mathrm{dl}, \mathrm{n}=39)$. The laboratory characteristics of the three groups are shown in Table 2.

In group $1(\mathrm{n}=39), 15$ subjects died, producing a mortality of $14.3 / 1000$ personmonths. In group 2 ( $n=78), 14$ subjects died, for a mortality of $5.7 / 1000$ person-months. In group $3(\mathrm{n}=39), 12$ subjects died, resulting in a mortality of 13.3/1000 person-months (Table 3). The Kaplan-Meier survival curves of the UA groups are shown in Figure 1. 


\section{Kidney \\ Blood Pressure Research}

Kidney Blood Press Res 2013;37:181-189

DOI: 10.1159/000350143

Publisned ontrne: IVIal ZI, 2013

(C) 2013 S. Karger AG, Basel

www.karger.com/kbr

Feng/Jiang/Shi/Shen/Shi/Jin/Zeng/Wang: UA Levels and All-Cause Mortality in PD Patients
Table 1. Patient demographic characteristics $(n=156)$

\begin{tabular}{lc}
\hline Variables & $\begin{array}{c}\text { Means } \pm \text { SD or } \\
\text { counts (\%) }\end{array}$ \\
\hline Age (years) & $59.2 \pm 17.7$ \\
Female & $58(37)$ \\
Body mass index $\left(\mathrm{kg} / \mathrm{m}^{2}\right)$ & $22.8 \pm 3.8$ \\
Etiology of ESRD & \\
Chronic glomerulonephritis & $95(61)$ \\
Diabetic nephropathy & $24(15)$ \\
Hypertensive nephropathy & $18(12)$ \\
Other & $19(12)$ \\
Comorbid conditions & \\
Diabetes mellitus & $39(25)$ \\
Hypertension & $143(92)$ \\
Congestive heart failure & $26(17)$ \\
Ischemic heart disease & $8(5)$ \\
Cerebrovascular accident & $13(8)$ \\
\hline
\end{tabular}

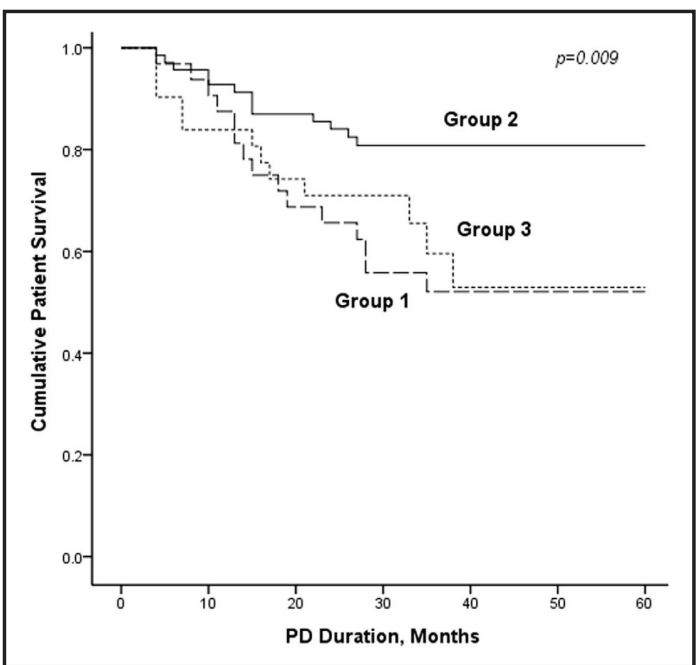

Fig. 1. Kaplan-Meier survival curves of patients in different UA level groups (before PD, group 2 was used as the reference group).

Table 2. Comparison of the characteristics of the three UA groups $(n=156)$

\begin{tabular}{|c|c|c|c|c|}
\hline Clinical parameters & $\begin{array}{l}\text { Group } 1(\mathrm{n}=39) \\
\mathrm{UA} \leq 7.0 \mathrm{mg} / \mathrm{dl}\end{array}$ & $\begin{array}{c}\text { Group } 2(\mathrm{n}=78) \\
\text { UA } 7.0-10.0 \mathrm{mg} / \mathrm{dl}\end{array}$ & $\begin{array}{l}\text { Group } 3(n=39) \\
U A \geq 10.0 \mathrm{mg} / \mathrm{dl}\end{array}$ & p-value \\
\hline Age (years) & $55.6 \pm 17.7$ & $54.1 \pm 16.9$ & $52.7 \pm 18.2$ & NS \\
\hline Body mass index $\left(\mathrm{kg} / \mathrm{m}^{2}\right)$ & $22.3 \pm 3.1$ & $22.8 \pm 3.7$ & $23.5 \pm 4.4$ & NS \\
\hline Systolic blood pressure (mmHg) & $151 \pm 28$ & $153 \pm 29$ & $153 \pm 25$ & NS \\
\hline Diastolic blood pressure (mmHg) & $88 \pm 15$ & $91 \pm 18$ & $92 \pm 17$ & NS \\
\hline Serum uric acid (mg/dl) & $5.9 \pm 1.0$ & $8.4 \pm 0.8$ & $11.3 \pm 1.0$ & - \\
\hline Serum albumin $(\mathrm{g} / \mathrm{dl})$ & $2.9 \pm 0.6$ & $3.1 \pm 0.5$ & $3.3 \pm 0.6$ & 0.012 \\
\hline Hemoglobin $(\mathrm{g} / \mathrm{dl})$ & $8.7 \pm 2.0$ & $8.6 \pm 1.9$ & $8.5 \pm 1.9$ & NS \\
\hline Phosphate (mg/dl) & $5.4 \pm 1.4$ & $5.5 \pm 1.3$ & $6.5 \pm 1.6$ & $<0.001$ \\
\hline $\mathrm{CRP}(\mathrm{mg} / \mathrm{l})^{*}$ & $4.4(3.0,9.1)$ & $5.7(4.0,7.0)$ & $4.5(4.0,9.3)$ & NS \\
\hline Diabetes mellitus (\%) & 39 & 24 & 12 & 0.032 \\
\hline KT/V urea+ & $1.87 \pm 0.46$ & $1.92 \pm 0.53$ & $1.77 \pm 0.38$ & NS \\
\hline $\mathrm{RRF}\left(\mathrm{ml} / \mathrm{min} / 1.73 \mathrm{~m}^{2}\right)+$ & $0.48 \pm 0.52$ & $0.71 \pm 0.68$ & $0.52 \pm 0.43$ & NS \\
\hline $\mathrm{D} / \mathrm{P}$ creatinine ratio at $4 \mathrm{~h}^{+}$ & $0.60 \pm 0.11$ & $0.61 \pm 0.11$ & $0.63 \pm 0.12$ & NS \\
\hline nPCR $(\mathrm{g} / \mathrm{kg} / \mathrm{d})$ & $0.89 \pm 0.21$ & $0.87 \pm 0.19$ & $0.84 \pm 0.22$ & NS \\
\hline
\end{tabular}

CRP, C-reactive protein ; RRF, residual renal function; nPCR, normalized protein catabolic rate. ${ }^{*}$ Expressed as the median (interquartile range); +after undergoing PD for $3.3 \pm 1.4$ months

Table 3. Deaths and technique failures in the three UA groups

\begin{tabular}{lcccc}
\hline Death & Total $(\mathrm{n}=156)$ & Group 1 (n=39) & Group 2 (n=78) & Group 3 (n=39) \\
& 41 & 15 & 14 & 12 \\
\hline Cardiovascular death & 23 & 7 & 9 & 7 \\
Non-cardiovascular death & 18 & 8 & 5 & 5 \\
Transfer to hemodialysis & 19 & 5 & 8 & 6 \\
Transfer to renal transplantation & 5 & 2 & 1 & 2 \\
Continuation of PD & 91 & 17 & 55 & 19 \\
Follow-up time (months) & $31.3 \pm 17.5$ & $33.3 \pm 20.8$ & $38.9 \pm 18.6$ & $33.3 \pm 17.8$ \\
Mortality (per 1000 person-months) & 9.8 & $14.3^{*}$ & 5.7 & $13.3^{*}$ \\
\hline * p $<0.05$; group 2 was used as the reference group. & \multicolumn{4}{c}{} \\
\hline
\end{tabular}




\section{Kidney \\ Bloód Pressure Research}

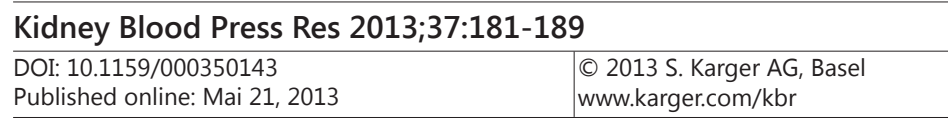

www.karger.com/kbr

Feng/Jiang/Shi/Shen/Shi/Jin/Zeng/Wang: UA Levels and All-Cause Mortality in PD Patients

Table 4. Predictors of mortality in peritoneal dialysis patients (univariate Cox regression analysis)

\begin{tabular}{lccc}
\hline Variables & $\mathrm{B}$ & Hazard Ratio $(95 \% \mathrm{CI})$ & $\mathrm{p}$-value \\
\hline Albumin (per 1 g/dl decrease) & 1.630 & $5.11(2.78-9.38)$ & $<0.001$ \\
Age (per 10-year increase) & 0.581 & $1.79(1.42-2.45)$ & $<0.001$ \\
Diabetes mellitus & 1.181 & $3.26(1.74-6.09)$ & $<0.001$ \\
Hypertensive nephropathy & 1.335 & $3.80(1.85-7.82)$ & $<0.001$ \\
Log CRP & 1.524 & $4.59(2.32-9.06)$ & $<0.001$ \\
Phosphate & 0.607 & $2.13(1.04-4.37)$ & 0.039 \\
RRF & 1.599 & $4.95(1.78-13.75)$ & 0.002 \\
UA groups* & & & 0.035 \\
Group 1 & 0.659 & $2.48(1.20-5.10)$ & 0.015 \\
Group 3 & 0.892 & $2.17(0.99-4.64)$ & 0.052 \\
\hline
\end{tabular}

$\mathrm{CI}$, confidence interval; CRP, C-reactive protein, $\mathrm{P}$, phosphate; RRF, residual renal function; * ${ }^{*}$ group 2 was used as the reference group.

Table 5. UA groups(before PD initiation) as an independent predictor of mortality in peritoneal dialysis patients (multivariate Cox regression analysis)

\begin{tabular}{lccc}
\hline Variables & $\mathrm{B}$ & Hazard Ratio (95\% CI) & p-value \\
\hline Albumin(per 1g/dl decrease) & 1.322 & $3.11(1.86-7.58)$ & $<0.001$ \\
Age(per 10-year increase) & 0.384 & $1.47(1.13-1.90)$ & 0.004 \\
Diabetes mellitus & 0.921 & $2.27(1.11-4.66)$ & 0.025 \\
Hypertensive nephropathy & 0.794 & $2.21(1.04-4.71)$ & 0.039 \\
RRF & 1.135 & $3.11(1.02-9.44)$ & 0.045 \\
UA groups* & & & 0.032 \\
Group 1 & 0.140 & $1.15(0.20-2.57)$ & 0.733 \\
Group 3 & 1.086 & $2.96(1.29-6.80)$ & 0.010 \\
\hline
\end{tabular}

* Use group 2 as reference ; CI, confidence interval.

three months. The serum UA decreased from $8.5 \pm 2.1 \mathrm{mg} / \mathrm{dl}$ before PD to $7.7 \pm 1.5 \mathrm{mg} / \mathrm{dl}$ after PD $(\mathrm{p}<0.001)$. There was a significant association between the UA concentrations before and after dialysis $(r=0.602, \mathrm{p}<0.001)$.

The same method described above was used to assign the patients to three groups according to the percentile of the serum UA levels: group $A, \leq 25^{\text {th }}$ percentile (UA $\leq 6.6 \mathrm{mg} /$ $\mathrm{dl}, \mathrm{n}=39)$; group $\mathrm{B}, 26^{\text {th }}-75^{\text {th }}$ percentile $(6.6<\mathrm{UA}<8.6 \mathrm{mg} / \mathrm{dl}, \mathrm{n}=78)$; and group $\mathrm{C}, \geq 76^{\text {th }}$ percentile $(\mathrm{UA} \geq 8.6 \mathrm{mg} / \mathrm{dl}, \mathrm{n}=39$ ). Mean concentrations for group $\mathrm{A}, \mathrm{B}$ and $\mathrm{C}$ were $5.8 \pm 0.5 \mathrm{mg}$ / $\mathrm{dl}, 7.7 \pm 0.6 \mathrm{mg} / \mathrm{dl}$ and $9.7 \pm 0.8 \mathrm{mg} / \mathrm{dl}$, respectively.

\section{Cox Regression Analysis of PD Patient Mortality}

As shown in Table 4, age, underlying hypertensive nephropathy (HTN), comorbidity with DM, serum albumin, CRP, phosphate, RRF and UA group were related to mortality in PD patients according to the results of a univariate Cox regression model. According to a multivariate Cox regression model using group 2 as the reference group (Table 5), the HR of group 1 was 1.15 (95\% CI $0.20-2.57, \mathrm{p}=0.733)$, and the HR of group 3 was 2.96 (95\% CI 1.29-6.80, $\mathrm{p}=0.01)$.

The relationship between the UA levels after PD and mortality was also examined. According to a univariate Cox regression model using group $B$ as the reference group, the hazard ratio (HR) of group A was 2.17 (95\% confidence interval [CI] 1.03-4.56, p=0.041), and the HR of group C was 2.39 (95\% CI 1.12-5.11, p=0.025).The Kaplan-Meier survival 


\section{Kidney \\ Blood Pressure Research}

\section{Kidney Blood Press Res 2013;37:181-189}

DOI: 10.1159/000350143

Published onIIne: IVIaI 2I, 2013

C 2013 S. Karger AG, Basel

Feng/Jiang/Shi/Shen/Shi/Jin/Zeng/Wang: UA Levels and All-Cause Mortality in PD Patients

Table 6. UA groups (after PD 3 months) as an independent predictor of mortality in peritoneal dialysis patients (multivariate Cox regression analysis)

\begin{tabular}{lccc}
\hline Variables & $\mathrm{B}$ & Hazard Ratio (95\% CI) & $\mathrm{p}$-value \\
\hline ALB(per 1g/dl decrease) & 1.353 & $3.87(1.88-7.96)$ & $<0.001$ \\
Age(per 10-year increase) & 0.567 & $1.76(1.33-2.33)$ & $<0.001$ \\
Diabetes mellitus & 0.717 & $2.05(1.05-4.19)$ & 0.041 \\
Hypertensive nephropathy & 1.19 & $3.29(1.51-7.18)$ & 0.003 \\
RRF & 1.711 & $5.53(1.91-15.98)$ & 0.002 \\
UA groups* & & & $<0.001$ \\
Group A & 0.113 & $0.89(0.39-2.05)$ & 0.790 \\
Group C & 1.68 & $5.36(2.26-12.71)$ & $<0.001$ \\
\hline
\end{tabular}

* Use group B as reference ; CI, confidence interval ; ALB, albumin.

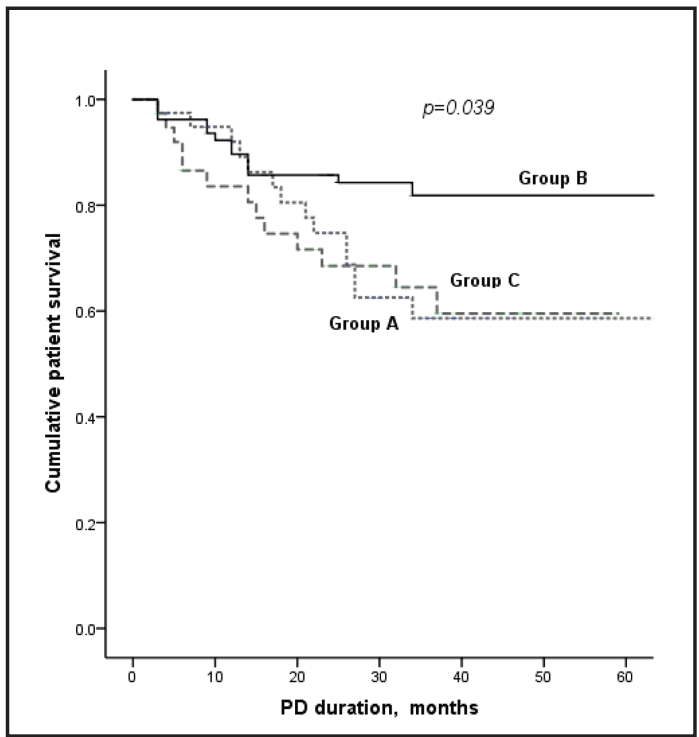

Fig. 2. Kaplan-Meier survival curves of patients in different UA level groups (3 months after PD, Group $\mathrm{B}$ was used as the reference group).

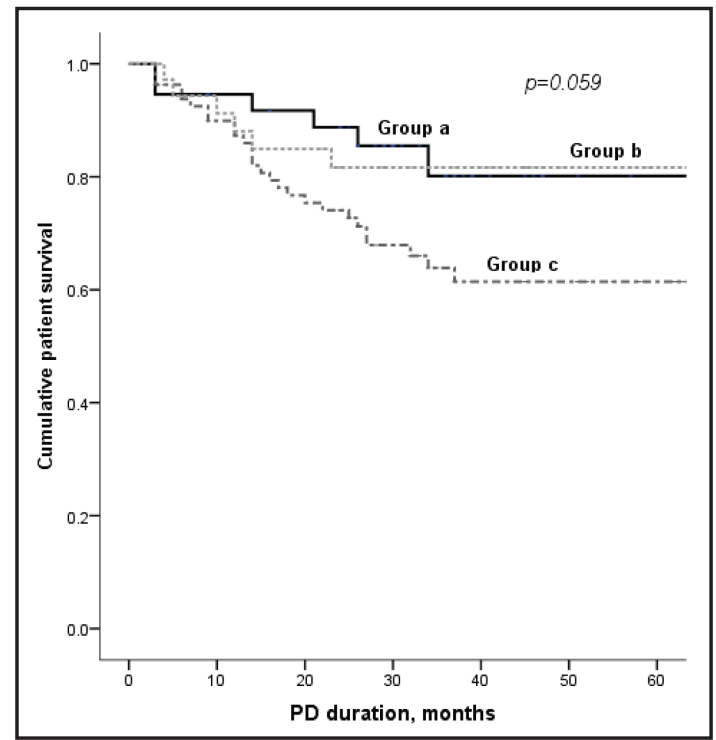

Fig. 3. Kaplan-Meier survival curves of patients with changed UA groups before and after PD initiation. Group a, changed from a lower UA group into a higher group; Group b, changed from a higher UA group into a lower group; Group c, remained in a similar group.

curves of the UA groups are shown in Figure 2. In a multivariate Cox regression model using group B as the reference group (Table 6), the hazard ratio (HR) of group A was 0.89 ( $95 \%$ confidence interval [CI] 0.39-2.05, p=0.790), and the HR of group C was $5.36(95 \%$ CI 2.26-12.71, p<0.001).

After PD initiation, 39 subjects in group1 changed to group A $(n=20)$, group $B(n=18)$ and group $C(n=1)$. In group 2,78 subjects changed to group $A(n=18)$, group $B(n=42)$ and group $C(n=18)$. In group 3,39 subjects changed to group $A(n=1)$, group $B(n=19)$ and group $\mathrm{C}(\mathrm{n}=19)$. There were 38 subjects changed from a higher UA group into a lower UA group (group a). There were 37 subjects changed from a lower UA group into a higher UA group (group b). Other subjects were divided into group c $(n=91)$. Patients who remained in the similar UA group after PD initiation showed a higher mortality with a marginally significance. The Kaplan-Meier survival curves of the UA groups are shown in Figure 3. 


\section{Kidney Blood Pressure Research}

Kidney Blood Press Res 2013;37:181-189

DOI: 10.1159/000350143 2013 S. Karger AG, Basel

Published onine: IVIal ZI, 2013

www.karger.com/kbr

Patients

\section{Discussion}

To the best of our knowledge, this is the first study to examine the relationship between serum UA levels and all-cause mortality in PD patients. Our results demonstrate that the highest quartiles of UA levels were associated with a poorer outcome and that a higher UA level was an independent risk factor for all-cause mortality in the PD patients. Though a lower serum UA level was associated with elevated mortality in the PD patients, this effect disappeared after adjustment for concurrent situation such as malnutrition and DM.

In our study population, a relatively high proportion of ESRD was caused by glomerulonephritis, whereas the incidence of ESRD caused by DM and hypertension was lower. However, a previous study showed a similar result with regard to the etiology of ESRD in China [12]. The reason for this result may be the difference in ethnicity or the status of China as a developing country.

Consistent with previous studies of hemodialysis patients [5, 6], our results showed that a higher UA level was an independent risk factor for all-cause mortality in dialysis patients. However, two other studies [7,8] have demonstrated that a lower, not a higher, UA level was an independent risk factor for all-cause and cardiovascular disease (CVD) mortality in hemodialysis patients, which differs from the results of the present study. In patients diagnosed with hypertension [13] and DM [14], a J-shaped relationship has been found between serum UA levels and CVD mortality, which also demonstrates an association between a higher UA level and a poor outcome.

Numerous studies have confirmed that elevated serum UA is associatedwith CVD and all-cause mortality [3, 4, 15-17]. In this study, a higher UA level was an independent risk factor for all-cause mortality in PD patients although the group 3 patients, who exhibited higher UAlevels and poor outcomes, had a better nutritional status compared with the group 2 patients. Several mechanisms, which remain to be clarified, may be responsible for the relationship between a higher UA level and mortality in PD. First, different studies have supported the hypothesis that UA is an endothelial toxin and that hyperuricemia causes vascular disease via endothelial dysfunction. Hyperuricemia is associated with impaired nitric oxide production, which activates the renin-angiotensin system and induces endothelial dysfunction $[18,19]$. The direct infusion of serum UA into the human brachial artery has been shown to cause endothelial dysfunction [20]. Second, UA levels have been positively correlated with insulin resistance, dyslipidemia, hypertension and atherosclerosis [2, 21, 22]. Additionally, elevated UA concentrations have been correlated with rheological disturbances, such as impaired platelet adhesion and aggregation [23]. The reasons mentioned above may relate to cardiovascular events and mortality in PD patients. Finally, elevated UA concentrations cause an accelerated decline in residual renal function [10], which is a strong predictor of patient and technique survival in PD patients [24, 25].

In the current study, the PD patient group with the lowest UA level exhibited increased mortality, but after adjusting for serum albumin levels and DM, this relationship was no longer significant. A decreased UA concentration may be a reflection of poor nutrition. After adjusting for serum albumin levels, group 1 showed a decreased HR $(1.82,95 \%$ CI 0.86-3.87) that was not significantly different $(\mathrm{p}=0.118)$ from that of the group 2 cohort. Furthermore, DM has already been established as a risk factor for mortality in PD. In this study, the elevated mortality in the group 1 cohort may have been caused by the higher incidence of DM, which is in accordance with a study reported by Lee SM et al. [7].

In this study, PD lowered UA levels but had no influence on the associations of mortality with UA levels. The UA concentrations in group 1 and group A were close $(5.9 \pm 1.0 \mathrm{mg} / \mathrm{dl}$ vs $5.8 \pm 0.5 \mathrm{mg} / \mathrm{dl}$ ). In this set of patients, diabetes and malnutrition may increase all-cause mortality. Though group C showed a lower level of UA than group $3(9.7 \pm 0.8 \mathrm{mg} / \mathrm{dl} v s 11.3 \pm 1.0$ $\mathrm{mg} / \mathrm{dl}$ ), the concentration was still much higher than normal and may cause poor outcome. Furthermore, patients who remained in the similar UA group after PD initiation showed a higher mortality with a marginally significance (Figure 3). The reason for this phenomenon is not well known and need further investigation. 


\section{Kidney Blood Pressure Research}

A limitation of this study is that it was conducted in a single center and had a relatively small sample size. Due to the retrospective nature of the study, some potentially important characteristics, such as SGA scores and comorbidity index scores, were not examined.

\section{Conclusion}

Our results demonstrate that in PD patients, a higher serum UA level is related to increased mortality and is an independent risk factor for all-cause mortality. The presence of other comorbidities such as DM or malnutrition may elevate mortality in PD patients with lower serum UA. To confirm this relationship and to clarify the underlying mechanisms, additional studies in larger PD populations should be conducted.

\section{Conflict of Interests}

We certify that all authors have no financial or other conflict of interests in connection with the submitted article.

\section{Reference}

1 Niskanen LK, Laaksonen DE, Nyyssonen K, Alfthan G, Lakka HM, Lakka TA, Salonen JT: Uric acid level as a risk factor for cardiovascular and all-cause mortality in middle-aged men: A prospective cohort study. Arch Intern Med 2004;164:1546-1551.

$\checkmark 2$ Iwashima Y, Horio T, Kamide K, Rakugi H, Ogihara T, Kawano Y: Uric acid, left ventricular mass index, and risk of cardiovascular disease in essential hypertension. Hypertension 2006;47:195-202.

-3 Chen JH, Chuang SY, Chen HJ, Yeh WT, Pan WH: Serum uric acid level as an independent risk factor for all-cause, cardiovascular, and ischemic stroke mortality: A chinese cohort study. Arthritis Rheum 2009;61:225-232.

4 Madero M, Sarnak MJ, Wang X, Greene T, Beck GJ, Kusek JW, Collins AJ, Levey AS, Menon V: Uric acid and long-term outcomes in ckd. Am J Kidney Dis 2009;53:796-803.

$>5$ Hsu SP, Pai MF, Peng YS, Chiang CK, Ho TI, Hung KY: Serum uric acid levels show a 'j-shaped' association with all-cause mortality in haemodialysis patients. Nephrol Dial Transplant 2004;19:457-462.

-6 Suliman ME, Johnson RJ, Garcia-Lopez E, Qureshi AR, Molinaei H, Carrero JJ, Heimburger O, Barany P, Axelsson J, Lindholm B, Stenvinkel P: J-shaped mortality relationship for uric acid in ckd. Am J Kidney Dis 2006;48:761-771.

7 Lee SM, Lee AL, Winters TJ, Tam E, Jaleel M, Stenvinkel P, Johnson RJ: Low serum uric acid level is a risk factor for death in incident hemodialysis patients. Am J Nephrol 2009;29:79-85.

-8 Latif W, Karaboyas A, Tong L, Winchester JF, Arrington CJ, Pisoni RL, Marshall MR, Kleophas W, Levin NW, Sen A, Robinson BM, Saran R: Uric acid levels and all-cause and cardiovascular mortality in the hemodialysis population. Clin J Am Soc Nephrol 2011;6:2470-2477.

-9 Tang Z, Cheng LT, Li HY, Wang T: Serum uric acid and endothelial dysfunction in continuous ambulatory peritoneal dialysis patients. Am J Nephrol 2009;29:368-373.

-10 Park JT, Kim DK, Chang TI, Kim HW, Chang JH, Park SY, Kim E, Kang SW, Han DS, Yoo TH: Uric acid is associated with the rate of residual renal function decline in peritoneal dialysis patients. Nephrol Dial Transplant 2009;24:3520-3525.

11 Klein R, Klein BE, Cornoni JC, Maready J, Cassel JC, Tyroler HA: Serum uric acid. Its relationship to coronary heart disease risk factors and cardiovascular disease, evans county, georgia. Arch Intern Med 1973;132:401-410. 


\section{Kidney \\ Blood Pressure Research}

Kidney Blood Press Res 2013;37:181-189

\begin{tabular}{l|l}
\hline DOI: $10.1159 / 000350143$ & (c) 2013 S. Karger AG, Basel
\end{tabular}

Published onlIne: IVar 21, 2013

www.karger.com/kbr Patients

12 Etiology of end-stage renal disease reported SOCIETY OF NEPHROLOGY, CHINESE MEDICAL ASSOCIATION: The report about the registration of dialysis and transplantation in China. Chin J Nephrol 2001:17;77-78.

13 Verdecchia P, Schillaci G, Reboldi G, Santeusanio F, Porcellati C, Brunetti P: Relation between serum uric acid and risk of cardiovascular disease in essential hypertension. The piuma study. Hypertension 2000;36:1072-1078.

14 Mazza A, Zamboni S, Rizzato E, Pessina AC, Tikhonoff V, Schiavon L, Casiglia E: Serum uric acid shows a j-shaped trend with coronary mortality in non-insulin-dependent diabetic elderly people. The cardiovascular study in the elderly (castel). Acta Diabetol 2007;44:99-105.

15 Ford ES: Uric acid and mortality from all-causes and cardiovascular disease among adults with and without diagnosed diabetes: Findings from the national health and nutrition examination survey III linked mortality study. Diabetes Res Clin Pract 2011;93:e84-86.

-16 Wu YQ, Li J, Xu YX, Wang YL, Luo YY, Hu DY, Liu WJ, Yang M, Pi L, Wang MS, Wang JY, Zhao SM, Li MJ: Predictive value of serum uric acid on cardiovascular disease and all-cause mortality in urban chinese patients. Chin Med J (Engl) 2010;123:1387-1391.

17 Holme I, Aastveit AH, Hammar N, Jungner I, Walldius G: Uric acid and risk of myocardial infarction, stroke and congestive heart failure in 417,734 men and women in the apolipoprotein mortality risk study (amoris). J Intern Med 2009;266:558-570.

18 Khosla UM, Zharikov S, Finch JL, Nakagawa T, Roncal C, Mu W, Krotova K, Block ER, Prabhakar S, Johnson RJ: Hyperuricemia induces endothelial dysfunction. Kidney Int 2005;67:1739-1742.

19 Yu MA, Sanchez-Lozada LG, Johnson RJ, Kang DH: Oxidative stress with an activation of the reninangiotensin system in human vascular endothelial cells as a novel mechanism of uric acid-induced endothelial dysfunction. J Hypertens 2010;28:1234-1242.

-20 Milionis HJ, Kalantzi KJ, Goudevenos JA, Seferiadis K, Mikhailidis DP, Elisaf MS: Serum uric acid levels and risk for acute ischaemic non-embolic stroke in elderly subjects. J Intern Med 2005;258:435-441.

21 Nakagawa T, Hu H, Zharikov S, Tuttle KR, Short RA, Glushakova O, Ouyang X, Feig DI, Block ER, HerreraAcosta J, Patel JM, Johnson RJ: A causal role for uric acid in fructose-induced metabolic syndrome. Am J Physiol Renal Physiol 2006;290:F625-631.

22 Yamamoto Y, Ogino K, Igawa G, Matsuura T, Kaetsu Y, Sugihara S, Matsubara K, Miake J, Hamada T, Yoshida A, Igawa O, Yamamoto T, Shigemasa C, Hisatome I: Allopurinol reduces neointimal hyperplasia in the carotid artery ligation model in spontaneously hypertensive rats. Hypertens Res 2006;29:915-921.

-23 Johnson RJ, Kang DH, Feig D, Kivlighn S, Kanellis J, Watanabe S, Tuttle KR, Rodriguez-Iturbe B, HerreraAcosta J, Mazzali M: Is there a pathogenetic role for uric acid in hypertension and cardiovascular and renal disease? Hypertension 2003;41:1183-1190.

-24 Termorshuizen F, Korevaar JC, Dekker FW, van Manen JG, Boeschoten EW, Krediet RT: The relative importance of residual renal function compared with peritoneal clearance for patient survival and quality of life: An analysis of the netherlands cooperative study on the adequacy of dialysis (necosad )-2. Am J Kidney Dis 2003;41:1293-1302.

25 Haag-Weber M: The impact of residual renal function on survival. Nephrol Dial Transplant 2008;23:21232126. 